\title{
Effects of ketamine, propofol, and ketofol on proinflammatory cytokines and markers of oxidative stress in a rat model of endotoxemia-induced acute lung injury
}

\author{
Derya Gokcinar ${ }^{1}, V_{\text {Volkan Ergin }}^{2}$, Ahmet Cumaoglu ${ }^{\circledR}$, Adnan Menevse ${ }^{2}$ and Aysel Aricioglu ${ }^{4}$ \\ 1Ankara Numune Training and Research Hospital, Department of Anesthesiology, Ankara, Turkey; ${ }^{2}$ Gazi University, Faculty of Medicine, Depart- \\ ment of Medical Biology and Genetic, Ankara, Turkey; ${ }^{3}$ Erciyes University, Faculty of Pharmacy, Department of Biochemistry, Kayseri, Turkey; \\ ${ }^{4}$ Gazi University, Faculty of Medicine, Department of Medical Biochemistry, Ankara, Turkey
}

\begin{abstract}
Intravenous lipopolysaccharide (LPS) leads to acute lung injury (ALI) in rats. The purpose of this study was to examine the anti-inflammatory and antioxidant efficacy of ketamine, propofol, and ketofol in a rat model of ALI. We induced ALI in rats via intravenous injection of LPS (15 $\left.\mathrm{mg} \mathrm{kg}^{-1}\right)$. The animals were randomly separated into five groups: control, LPS only, LPS + ketamine (10 $\left.\mathrm{mg} \cdot \mathrm{kg}^{-1} \cdot \mathrm{h}^{-1}\right)$, LPS + propofol $\left(10 \mathrm{mg} \cdot \mathrm{kg}^{-1} \cdot \mathrm{h}^{-1}\right)$, LPS + ketofol $\left(5 \mathrm{mg} \cdot \mathrm{kg}^{-1} \cdot \mathrm{h}^{-1}\right.$ ketamine $+5 \mathrm{mg} \cdot \mathrm{kg}^{-1} \cdot \mathrm{h}^{-1}$ propofol). LPS resulted in an increase in the release of proinflammatory cytokines, mRNA expression related with inflammation, production of nitric oxide, and lipid peroxidation. Ketamine prevented the increase in markers of oxidative stress and inflammation mediators, both in plasma and lung tissue. Propofol decreased the levels of cytokines in plasma and lung tissue, whereas it had no effect on the IL-1-beta level in lung tissue. Ketamine downregulated mediators of lung tissue inflammation and reduced the level of circulating cytokines and protected lung tissue against lipid peroxidation. Ketofol decreased the level of TNF- $\alpha$ and IL-1 $\beta$ in plasma, as well as expression of cyclooxygenase- 2 mRNA and the nitrate/nitrite level in lung tissue. The results of this investigation support the hypothesis that ketamine may be effective in preventing ALI.
\end{abstract}

Key words: lipopolysaccharide, acute lung injury, oxidative stress, ketamine, propofol, ketofol

Received: 04 April, 2013; revised: 09 August, 2013; accepted: 27 August, 2013; available on-line: 11 September, 2013

\section{INTRODUCTION}

Acute lung injury (ALI) and its more severe form, acute respiratory distress syndrome (ARDS), are devastating disorders of overwhelming pulmonary inflammation and hypoxemia, resulting in high morbidity and mortality (Randolph, 2009). Most patients with severe sepsis develop ALI (Bone et al., 1997; Ware et al., 2000). The management of patients with acute lung injury should be approached with four principal goals: (1) cardiopulmonary resuscitation and stabilization; (2) rapid identification and elimination of the cause of lung injury; (3) achieving adequate tissue oxygen delivery and support of other end-organs; and (4) prevention, recognition, and aggressive treatment of any complications that develop during the course of therapy (Marinelli \& Ingbar, 1994). At the molecular plane sepsis is related to activation of transcrip- tion factor nuclear factor-kappa B (NF-xB). During endotoxemia NF- $x \mathrm{~B}$ is activated by LPS (Baeuerle, 1998.). A higher level of pulmonary NF- $x \mathrm{~B}$ activation correlates with poor prognosis of sepsis- induced ALI. Once activated, NF- $x \mathrm{~B}$ dissociates from its inhibitors and translocates to the nucleus, where it induces expression of various pro-inflammatory and chemotactic agents, cytokines, cyclooxygenase-2 (COX-2), prostaglandins, inducible nitric oxide synthase (iNOS), oxygene free radicals, and other mediators, creating a self-maintaining inflammatory cycle (Karin et al., 2000; Baetz et al., 2005).

Propofol is an alkylphenol derivative with hypnotic properties (James \& Glen, 1980). It is commonly used as a sedative for patients on mechanical ventilation in intensive care units (Barrientos-Vega et al., 1997; Sztark et al., 2008). Propofol also has antioxidant properties (Murphy et al., 1992). In addition, administration of propofol causes suppression of cellular inflammatory responses. Immunomodulatory effects of propofol on neutrophils and leukocytes have been reported (Gao et al., 2003; Gao et al., 2006). Ketamine produces dissociative anesthesia by blocking N-methyl-D-aspartate (NMDA) receptors (White et al., 1982; Irifune et al., 1992), and has anti-inflammatory, antioxidant and immunsupressive effects (Koga et al., 1994; Kawasaki et al., 1999; Tanguchi \& Yamomoto, 2005, Liu et al., 2012). Ketofol is a mixture of ketamine and propofol, a recent addition to the pharmaceutical armamentarium for sedation in both adults and children (Loh \& Dalen, 2007; Willman \& Andolfatto, 2007; Andolfatto \& Willman, 2010; Khutia et al., 2012; Min et al., 2012). Ketamine elevates blood pressure (Ogawa et al., 1993) whereas propofol decreases blood pressure (Coates et al., 1985; Van Aken et al., 1988). The ketamine-propofol combination maintains hemodynamic stability in most patients (Loh et al., 2007). Although the effects of ketamine, propofol, and ketofol on sedation have been reported, their effects in ALI induced by LPS are unknown. This study aimed to compare the effects of ketamine, propofol, and ketofol on oxidative stress and anti-inflammatory processes in lung tissue in vivo rat model of endotoxemia.

e-mail: ahmetcumaoglu@yahoo.com

Abbreviations: ALI, Acute lung injury; COX-2, cyclooxygenase-2; LPS, Lipopolysaccharide; IL-1 $\beta$, interleukin-1 $\beta ;$ IL-6, interleukin-6 NF-KB, nuclear factor-kappa $B$; iNOS, inducible nitric oxide synthase; NMDA, N-methyl-D-aspartate; TBARS, thiobarbituric acid reactive substances; TNF-a, Tumor necrosis factor-a 


\section{MATERIALS AND METHODS}

Animal preparation and experimental protocol. This study included 30 female Wistar rats (Gazi University Experimental Animals Breeding and Research Center, Ankara, Turkey) weighing $250 \pm 50 \mathrm{~g}$ that were given a standard diet and water ad libitum. The study procedure has been accepted by the Gazi University Committee on Laboratory Animals (\#11-051), and the ethics of laboratory animal care (NIH publication No. 85-23, revised 1985) have been verified. Thiopentone sodium (Penthal ${ }^{\circledR} 30 \mathrm{mg} \mathrm{kg}^{-1}$ intraperitoneally [i.p.]) as anesthetic was administered to rats in all groups. Animals were positioned in the supine on a heating pad to keep a rectal temperature of $37^{\circ} \mathrm{C}$. Then, an arterial catheter (Intramedic, Clay Adams, Sparks, MD, USA) was implanted in the left femoral artery for the monitoring of mean arterial blood pressure and heart rate (Hewlett Packard Model 66S monitor, Saronno, Italy). Blood samples were obtained from the left femoral artery.

Experimental protocol. Acute systemic inflammation was triggered by intravenous bolus injection of lipopolysaccharide (LPS, $15 \mathrm{mg} \mathrm{kg}^{-1}$ ). We applied LPS from Escherichia coli serotype 0111:B4 (Sigma, St. Louis, MO, USA). The animals were separated into five experimental groups. The control group rats received a bolus intravenous injection of $0.9 \%$ saline $\left(1 \mathrm{~mL} \mathrm{~kg}^{-1}\right)$, followed by intravenous infusion of $0.9 \%$ saline $\left(1 \mathrm{~mL} \cdot \mathrm{kg}^{-1} \cdot \mathrm{h}^{-1}\right)$. Rats in this group did not receive the endotoxin. In the lipopolysaccharide (LPS) group, endotoxemia was induced via bolus injection of endotoxin (LPS, $15 \mathrm{mg}$ $\mathrm{kg}^{-1}$ ). In the LPS + ketamine group endotoxemia was induced via bolus injection of endotoxin (LPS $15 \mathrm{mg} \mathrm{kg-}$ 1) followed by intravenous administration of ketamine $\left(10 \mathrm{mg} \mathrm{kg}^{-1} \mathrm{~h}^{-1}\right)$ (Ketalar, Eczacibasi, TR). In the LPS + propofol group endotoxemia was induced as above followed by intravenous administration of propofol (10 $\mathrm{mg} \mathrm{kg}^{-1} \cdot \mathrm{h}^{-1}$ ) (Pofol, Dongkook Pharm. Co., Ltd.). In the LPS + ketofol group endotoxemia was induced as above followed by intravenous administration of ketofol (ketamine $5 \mathrm{mg} \cdot \mathrm{kg}^{-1} \cdot \mathrm{h}^{-1}+$ propofol $\left.5 \mathrm{mg} \cdot \mathrm{kg}^{-1} \cdot \mathrm{h}^{-1}\right)$. Blood samples were collected and the lungs were harvested $3 \mathrm{~h}$ following LPS injection.

Markers of oxidative stress and inflammatory mediators. Lung tissue samples were homogenized in $\mathrm{pH}$ 7.4 phosphate buffered saline containing a protease inhibitor cocktail. The homogenate was centrifuged at $10000 \mathrm{rpm}$ for $10 \mathrm{~min}$ to remove debris. Supernatant used for analysis of biochemical parameters. Thiobarbituric acid reactive substances (TBARS) were assayed according to (Uchiyama \& Mihara, 1978). Optical density of butanol phase determined on a microplate reader at $532 \mathrm{~nm}$ and compared with a tetramethoxypropane standard curve between 0 and $20 \mathrm{nmol}$. The level of nitrite/nitrate stable end products of nitric oxide (NO) in lung tissue was measured by the Griess reaction according to (Miranda et al., 2001). This test is based on chemical reduction of nitrate to nitrite with vanadium chloride. Then, it is transformed into an azo compound which is determined spectrophotometrically at $540 \mathrm{~nm}$.

Enzyme-linked immunosorbent assay. Tumor necrosis factor- $\alpha(\mathrm{TNF}-\alpha)$ and interleukin-1 $\beta$ (IL-1 $\beta$ ) in lung tissue and plasma levels were assayed using a sandwich enzyme-linked immunosorbent assay and commercially available kits (Invitrogen Life Technologies, Karlsruhe, Germany), in accordance with the manufacturer's instructions.

Quantitative real-time PCR. Total RNA isolation from tissue homogenate was performed via phenol-guanidine isothiocyanate extraction using RNAzol RT reagent (Molecular Research Center, Inc. Cincinnati, OH), according to the manufacturer's instructions. Total RNA (1 mg) was reverse-transcribed to cDNA using a Transcriptor First Strand cDNA Synthesis Kit (Roche Diagnostics $\mathrm{GmbH}$, Mannheim, Germany) in a $20-\mu \mathrm{L}$ reaction mixture. Random hexamers were utilized to lead the cDNA synthesis. Real-time PCR was carried out using a Light Cycler 480 II System (Roche Diagnostics GmbH, Mannheim, Germany). To quantify cDNA, qPCR was performed using LightCycler 480 Probe Master Mix and hydrolysis probes (TaqMan probe, Roche Diagnostics $\mathrm{GmbH}$, Mannheim, Germany). The primers and probes used for qPCR for each gene are shown in Table 1 . The reaction mixture $(20 \mu \mathrm{L})$ was prepared in a 96-well plate (Roche Diagnostics $\mathrm{GmbH}$, Mannheim, Germany) and included $10 \mu \mathrm{L}$ of $2 \times$ Light Cycler 480Master Reaction Mix (Roche Diagnostics GmbH, Mannheim, Germany), $0.25 \mathrm{pmol}$ of each primer (Alpha DNA, Montreal, QC, Canada), 1 pmol of probes, and $1 \mu \mathrm{L}$ of cDNA. Real-time PCR was performed in the following conditions: activation of Taq DNA polymerase and DNA denaturation at $95^{\circ} \mathrm{C}$ for $10 \mathrm{~min}$, followed by 50 amplification cycles for $10 \mathrm{~s}$ at $95^{\circ} \mathrm{C}$ and for $20 \mathrm{~s}$ at $60^{\circ} \mathrm{C}$, and a final cooling step to attain $40^{\circ} \mathrm{C}$. For each sample the level of target gene transcripts was normalized to $\beta$-actin.

Statistical analysis. Data are expressed as mean \pm standard deviation (S.D.). The Mann-Whitney U test was used for comparison between groups. Expression of the target gene mRNA relative to that of the housekeeping gene mRNA was analyzed by a relative expression software tool (REST 2009, v.2.0.13). The statistical significance was established via the pair-wise fixed reallocation randomization test (Pfaffl et al., 2002). $P$ values $<0.05$ considered statistically significant.

\section{RESULTS}

\section{Effects of LPS and anesthetics on the level of TNF- $a$ in plasma and lung tissue}

LPS infusion resulted in a significant increase in the level of TNF- $\alpha$ in plasma and lung tissue $(p<0.05)$. Ketamine or propofol treatment decreased the level of

Table 1. Gene-specific primer sequences and probe numbers used for real-time PCR.

\begin{tabular}{|c|c|c|c|}
\hline Gene & Forward primer & Reverse primer & Universal probe library No. \\
\hline b-actin & 5'-CCCGCGAGTACAACCTTCT-3' & $5^{\prime}$-CGTCATCCATGGCGAACT-3' & $\# 17$ \\
\hline NF-kB & $5^{\prime}-\mathrm{CTGGCAGCTCTTCTCAAAGC-3'}$ & $5^{\prime}$-CCAGGTCATAGAGAGGCTCAA-3' & \#68 \\
\hline COX-2 & $5^{\prime}-\mathrm{TCCAACCTCTCCTACTACACCAG-3'}$ & $5^{\prime}$-тCCAGAACTTCTTTTGAATCAGG-3' & \#69 \\
\hline iNOS & $5^{\prime}-$ TGATCTTGTGCTGGAGGTGA-3' & $5^{\prime}-$ GCAGCGCATACCACTTCAG-3' & \#128 \\
\hline IL-6 & $5^{\prime}-\mathrm{CCCTTCAGGAACAGCTATGAA}-3^{\prime}$ & $5^{\prime}-\mathrm{ACAACATCAGTCCCAAGAAGG-3^{ \prime }}$ & \#20 \\
\hline
\end{tabular}




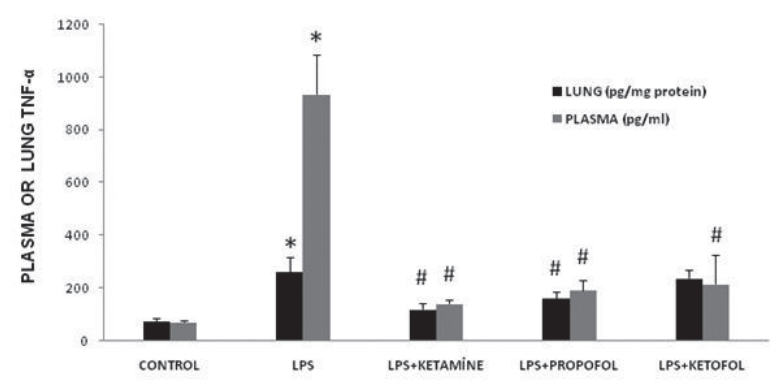

Figure 1. Effects of ketamine, propofol, and ketofol treatment on level of TNF-a in circulation and in lung tissue.

Results are shown as mean \pm S.D. ${ }^{*} p<0.05$ vs. control group. ${ }^{*} p<$ 0.05 vs. LPS group.

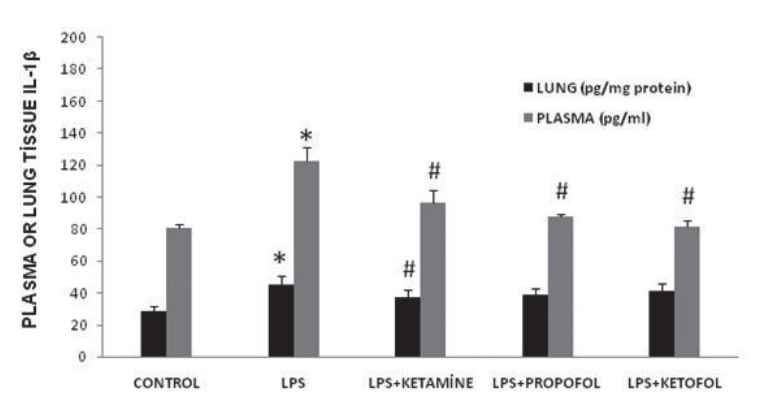

Figure 2. Effects of ketamine, propofol and ketofol treatment on level of IL-1 $\beta$ in circulation and in lung tissue.

Results are shown as mean \pm S.D. ${ }^{*} p<0.05$ vs. the control group. ${ }^{\#} p<0.05$ vs. LPS group.

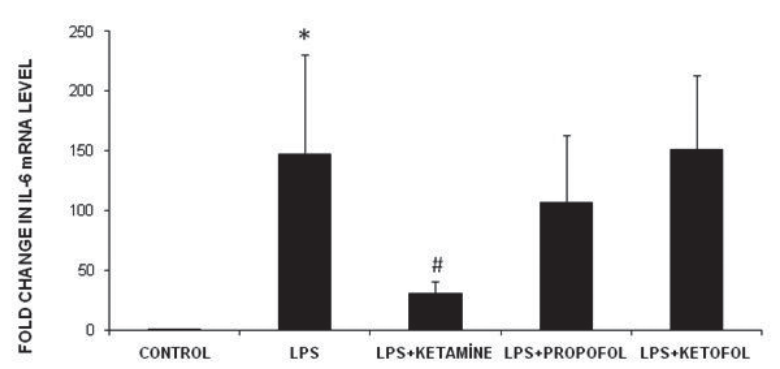

Figure 3. Effects of ketamine, propofol, and ketofol treatment on the level of IL-6 mRNA in lung tissue.

Results are shown as mean \pm S.D. ${ }^{*} p<0.05$ vs. control group. ${ }^{\#} p<$ 0.05 vs. LPS group.

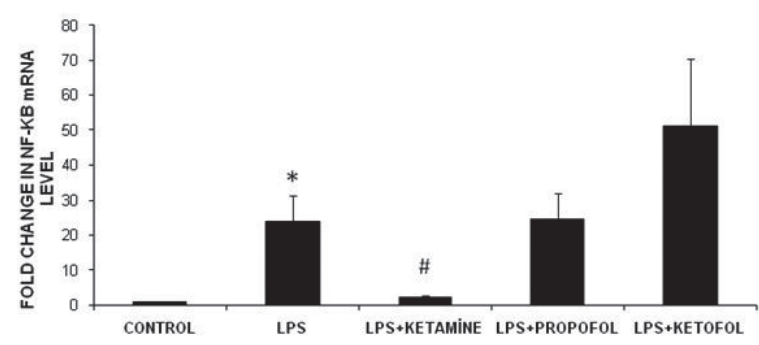

Figure 4. Effects of ketamine, propofol, and ketofol treatment on the level of NF-KB mRNA in lung tissue.

Results are shown as mean \pm S.D. ${ }^{*} p<0.05$ vs. control group. ${ }^{\#} p<0.05$ vs. LPS group.

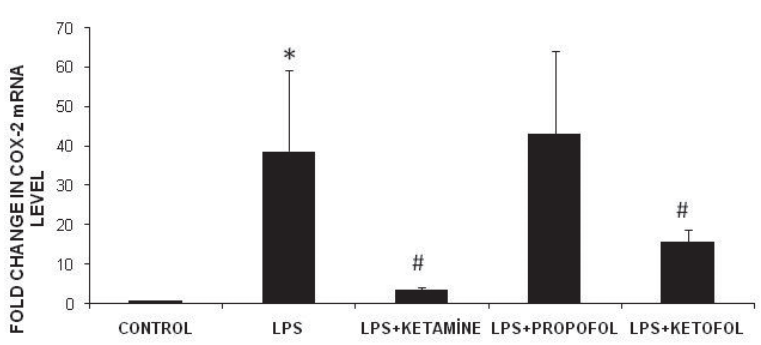

Figure 5. Effects of ketamine, propofol, and ketofol treatment on level of COX-2 mRNA in lung tissue.

Results are shown as mean \pm S.D. ${ }^{*} p<0.05$ vs control group. ${ }^{*} p<$ 0.05 vs. LPS group.

$\mathrm{TNF}-\alpha$ in both plasma and lung tissue $(p<0.05)$. Ketofol treatment caused a significant reduction in the plasma TNF- $\alpha$ level $(p<0.05)$, but had no effect on the $\mathrm{TNF}-\alpha$ level in lung tissue (Fig. 1).

Effects of LPS and anesthetics on the IL-1 $\beta$ level in plasma and lung tissue

As shown in Fig. 2, the level of IL-1 $\beta$ in plasma and lung tissue increased following by LPS administration $(p<0.05)$. Ketamine infusion post LPS administration caused a decrease in both plasma and lung tissue IL$1 \beta$ levels $(p<0.05)$. Propofol and ketofol decreased the IL-1 $\beta$ level in plasma $(p<0.05)$, but had no effect on its level in lung tissue.

\section{Effects of LPS and anesthetics on IL- 6 mRNA level in lung tissue}

IL-6 mRNA level was extremely high (147-fold) in lung tissue exposed to LPS-induced endotoxemia $(p<0.05)$. Ketamine treatment resulted in a significant reduction in IL-6 mRNA expression $(p<0.05)$. Propofol treatment decreased insignificantly. Ketofol treatment did not affect on IL-6 level.

\section{Effects of LPS and anesthetics on NF-KB mRNA expression in lung tissue}

NF- $x$ B mRNA expression was significantly $(p<0.05)$ higher (23.9-fold) in LPS group, when compared with those of control group. In the ketamine group there was a significant decrease in the level of NF- $x \mathrm{~B}$ expression $(p<0.05)$. Propofol treatment attenuated NF$x \mathrm{~B}$ expression insignificantly. There was not a significant difference in NF- $x \mathrm{~B}$ mRNA expression between the LPS and ketofol groups (Fig. 4).

\section{Effects of LPS and anesthetics on COX-2 mRNA expression}

COX-2 mRNA level increased significantly (38.7-fold) post LPS administration $(p<0.05)$ (Fig. 5). Both ketamine and ketofol treatment significantly decreased the level of COX-2 expression $(p<0.05)$. Propofol treatment did not affect COX-2 mRNA level (Fig. 5).

Effects of LPS and anesthetics on lung tissue inducible nitric oxide synthase (iNOS) expression and nitric oxide (NO) production

Administration of LPS resulted in an increase in iNOS expression (100.6-fold) (Fig. 6) and production of nitric oxide (the nitrate/nitrite level) (Fig. 7). Treatment 


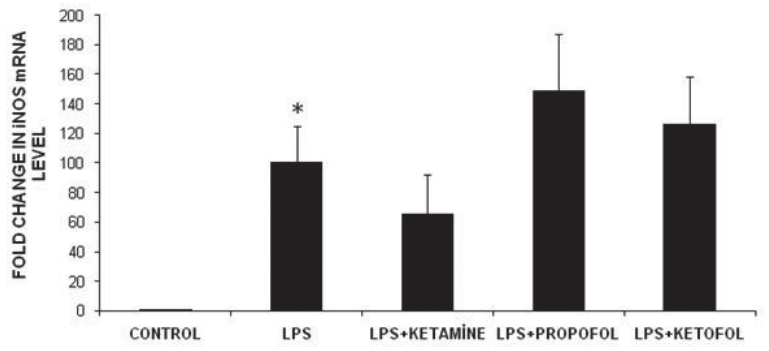

Figure 6. Effects of ketamine, propofol, and ketofol treatment on the level of iNOS mRNA in lung tissue.

Results are shown as mean \pm S.D. ${ }^{*} p<0.05$ vs. control group. ${ }^{\#} p<$ 0.05 vs. LPS group.

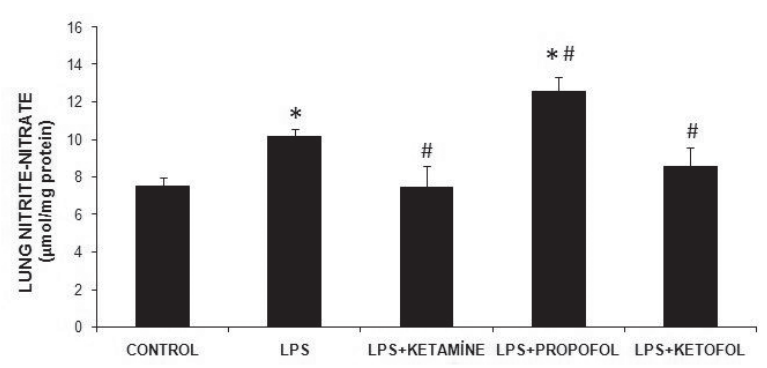

Figure 7. Effects of ketamine, propofol, and ketofol treatment on NO production (nitrate/nitrite level) in lung tissue.

Results are shown as mean \pm S.D. ${ }^{*} p<0.05$ vs. control group. ${ }^{*} p<$ 0.05 vs. LPS group.

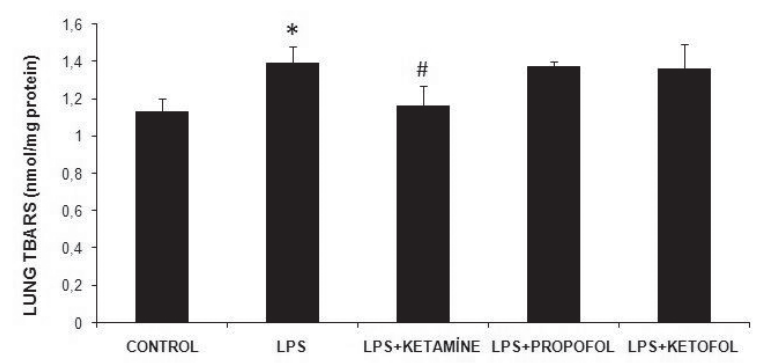

Figure 8. Effects of ketamine, propofol and ketofol, treatment on the level of TBARS in lung tissue.

Results are shown as mean \pm S.D. ${ }^{*} p<0.05$ vs. control group. ${ }^{*} p<$ 0.05 vs. LPS group.

with ketamine decreased the level of iNOS expression insignificantly. iNOS expression in the propofol and ketofol groups did not differ from that in the LPS group. Ketamine and ketofol caused a reduction in nitric oxide production $(p<0.05)$. Propofol treatment resulted in an increase in nitric oxide production $(p<0.05)$.

\section{Effects of LPS and anesthetics on thiobarbituric acid reactive substance (TBARS) concentration in lung tissue}

Induction of endotoxemia with LPS caused lipid peroxidation in lung tissue as evidenced by an increase in TBARS (Fig. 8). Ketamine treatment attenuated $(p<0.05)$ the TBARS concentration in lung tissue. Propofol and ketofol treatments had no effect on the production of TBARS.

\section{DISCUSSION}

LPS infusion resulted in an increase in the release of pro-inflammatory cytokines, mRNA expression associated with inflammation, production of nitric oxide, and lipid peroxidation. Ketamine prevented the increase in markers of oxidative stress and inflammation mediators. Although propofol and ketofol decreased the release of cytokines, they had no effect on tissue inflammation mediators or oxidative stress. ALI is the most common organ failure associated with Gram-negative bacteria-induced sepsis (Bernard et al., 1994; Bone et al., 1997; Ware \& Matthay, 2000; Rubenfeld et al., 2005). One of the mechanisms of injury involves the release of bacterial endotoxin into the circulation, which activates inflammatory cascades in the lungs, ultimately leading to lung damage (Brigham \& Meyrick, 1986). On the other hand, endotoxin release can result in changes in hemodynamic parameters, which can occur via the release of inflammatory cytokines and overproduction of free radicals and other oxidant mediators (Brierley \& Peters, 2008). LPS infusion can cause hemodynamic changes via increasing the level of circulating pro-inflammatory cytokines. Treatment with anesthetics in the present study resulted in a reduction in the level of cytokines. The observed suppressive effects of ketamine and propofol are similar to those previously reported (Larsen et al., 1998; Taniguchi et al., 2003; Shibakawa et al., 2005), but the present study is the first to report that ketofol reduced the level of cytokines in circulation. Hemodynamic changes can trigger activation of NF$x \mathrm{~B}$ - and NF-xB-dependent genes (Sheehan et al., 2002). In this context, the present study investigated the effects of anesthetics on NF- $x \mathrm{~B}$ expression in lung tissue in septic rats. In our study we found that upregulation of $\mathrm{NF}-x \mathrm{~B}$ expression in LPS group was inhibited by ketamine treatment. The present findings are in agreement with previously reported results (Sakai et al., 2000; Yu et al., 2007; Walters et al., 2010). Previous studies reported that ketamine administration resulted in the dysfunction of toll like receptor 4 pathway via interference with LPS-LBP (LBP; lipopolysaccharide binding protein) binding and reduction of LPS-induced increases in RAS activity, and then in the suppression of LPS induced signal transduction of MEK1/2, ERK1/2 and IKK (Chen et al., 2009). In addition to these, the translocation and transactivation of NF- $x \mathrm{~B}$ induced by LPS were depressed after exposure to ketamine. The anti-inflammatory effects of propofol have been shown in vitro and in vivo. Propofol has shown anti-inflammatory effect by decreasing cytokine levels in bronchoalveolar lavage fluid (BALF) of LPS-induced endotoxemic rats. Furthermore, LPS injection increased the mRNA and protein levels of inflammation releated genes, TRL4 and CD14 in lung parenchyma and propofol treatment decreased both mRNA and protein levels of CD14 and TRL4 (Ma et al., 2013). The present findings showed that propofol treatment reduced the level of circulating cytokines, but had no effect on NF- $x \mathrm{~B}$ mRNA level in lung tissue. The ability of propofol to reduce the level of circulating cytokines could be associated with its immunosuppressive effect (Takemoto, 2005). In contrast to the present findings, Gao et al., (Gao et al., 2003) reported that propofol inhibited $\mathrm{NF}-x \mathrm{~B}$ expression in lung tissue. The inconsistency between $\mathrm{Gao}$ and coworkers's results and those of the present study could be due to differences in the experimental conditions, 
such as LPS and propofol dosages. Previous studies have suggested that target genes for $\mathrm{NF}-x \mathrm{~B}$ are proinflammatory cytokines, including IL-1beta, IL-6, and TNF- $\alpha$ (Blackwell \& Christman, 1997). In the LPS group, the levels of lung tissue cytokine expression were significantly higher than that in the control group. Ketamine treatment suppressed the overproduction of cytokines, which may have been related to inhibition of $\mathrm{NF}-x \mathrm{~B}$ expression. Propofol decreased mRNA and protein levels of cytokines insignificantly; however, it did reduce the TNF- $\alpha$ level significantly without influencing IL- 6 mRNA suggesting that translational process can be targeted due to TRL4/TRIF/ p38/MK2 signaling (Gais et al., 2010); furthermore, IL-6 mRNA stabilization also requires p38 signaling (Zhao et al., 2007). Propofol had no effect on NF-xB mRNA level. The suppressive effect of propofol on translocation of $\mathrm{NF}-x \mathrm{~B}$ to the nucleus was reported by Gao et al., (2006). COX-2 is an inducible enzyme regulated by inflammation; its most abundant and potent product, prostaglandin E2 (PGE2), plays an important role in augmenting the inflammatory immune response in sepsis and ALI. The COX-2/PGE2 pathway has been shown to mediate inflammation by increasing vasodilation, vascular permeability, and ede$\mathrm{ma}$ in numerous respiratory diseases (Lappi-Blanco et al., 2006). In sepsis, bacterial endotoxin caused an induction of the COX-2/PGE2 pathway (Ang et al., 2011). Similarly, there was a significant increase in the COX-2 mRNA level post LPS administration in the present study and ketamine treatment caused the COX-2 mRNA level to decrease. A similar anti-inflammatory effect in the liver tissue of LPS-induced septic rats was reported by Suliburk et al., (2005). Moreover, inhibition of COX-2 prevented immune alterations and improved survival in cases of sepsis. As shown by Ahmad et al. (2002), inhibition of the COX2 activity using specific selective COX-2 inhibitor in septic rats also conferred benefit to the liver. Similarly, Callejas et al., (2001) reported that down regulation of COX-2 correlated with a decrease in tissue injury. In the present study, ketofol treatment moderately suppressed the COX-2 level without any effect on $\mathrm{NF}-x \mathrm{~B}$. The downregulation of COX -2 mRNA due to ketofol treatment without any effect on NF- $x \mathrm{~B}$ could be releated to COX-2 mRNA destabilization via influence of $\mathrm{p} 38 /$ mitogen-activated protein kinase-activated protein kinase 2 (MAPKAPK-2) signaling cascade (Lasa et al., 2000). Although the suppressive effects of propofol on COX-2 expression have been shown in polymorphonuclear cells (Gonzales-Correa et al., 2008; Inada et al., 2010), in the present study there was no significant difference in COX-2 expression between the propofol group and the LPS group. iNOS, another enzyme induced by inflammation, remains a focus of research on the relationship between NO and sepsis. Studies on NO and inflammation have primarily concentrated on the role of iNOS-derived NO (Thiemermann, 1997). Several studies reported that selective iNOS inhibition could have positive effects on various outcome variables in ALI and sepsis (Okamoto et al., 2000). In the present study iNOS mRNA level and nitrite/nitrate production increased in the lung tissue of rats post LPS administration. Treatment with ketamine resulted in a decrease in the nitrite/nitrate level and iNOS expression, but the decrease in iNOS expression was insignificant. The inconsistency between the findings for the iNOS and nitrite/nitrate levels following ketamine treatment may have been due to the fact that ketamine treatment could inhibit another isoform of NOS. Ketamine reduced NO biosynthesis by lowering the mRNA and protein levels of endotelial nitric oxide sythaese (eNOS) in umbilical vein endothelial cells in a time dependent manner (Chen et al., 2005). On the other hand, new data from experimental studies have implied that besides iNOSderived $\mathrm{NO}$ and neuronal nitric oxide sythase (nNOS)-derived NO may also be involved in the pathogenesis of ALI and sepsis (Gocan et al., 2000). According to Liu et al., (2009), high-dose propofol treatment $\left(30 \mathrm{mg} \mathrm{kg}^{-1} \mathrm{~h}^{-1}\right)$ caused a decrease in iNOS and increased the eNOS protein level in lung tissue in LPS administered rats, whereas in the present study propofol treatment had no effect on iNOS mRNA level; the difference in findings might be due to the difference in propofol doses. Propofol treatment increased levels of nitrite/ nitrate. Propofol has been reported to increase bioavaibility of endothelial-derived NO; this could contribute to a significant increase of nitrite/nitrate levels (Gragasisn et al., 2013). Extreme production of reactive oxygen species (ROS) has been shown in plasma and tissue samples of septic animals. Further, free radicals related with inflammation initiate oxidative stress that leads to organ failure as a result of tissue damage (Huet et al., 2011). Malondialdehyde (MDA) is measured using the TBARS assay and is a widely used marker of oxidative stress. Several studies have reported increased in MDA level in the pulmonary system and in other tissues following LPS injection (Shang et al., 2009; Qiao et al., 2011). Similarly, in the present study the MDA level in lung tissue in the LPS group was higher than that in the control group. Likewise, the increase in MDA was significantly attenuated in the ketamine group, but no such attenuation was observed in the other two treatment groups. Pro-oxidative effects of an increase in the MDA level in different cerebral structures of rats due to administration of ketamine at sub-anesthetic doses have been reported (da Silva et al., 2010). Although the protective effects of propofol against oxidative stress in different animal models (Vasileiou et al., 2010) and in cell cultures have been reported (Xu \& Wang, 2008), in the present study it had no effect on lipid peroxidation in lung tissue of septic rats.

In conclusion, ketamine infusion decreased the level of TNF- $\alpha$, IL- $1 \beta$, IL- $6, N^{2}-x B$, and COX- 2 mRNAs induced by LPS in lung tissue. Furthermore, ketamine reduced TNF- $\alpha$ and IL-1 $\beta$ levels in plasma, and decreased the nitrate/nitrite and TBARS levels in lung tissue. Propofol decreased the level of circulating $\mathrm{TNF}-\alpha$ and IL- $1 \beta$ in lung tissue, whereas it increased the nitrate/nitrite level. Ketofol reduced the level of TNF- $\alpha$ and IL-1 $\beta$ in plasma. Ketofol treatment resulted in a decrease in the level of COX-2 mRNA and in nitrate/nitrite level in lung tissue. Ketamine was observed to have broad anti-inflammatory and anti-oxidant properties in ALI. The ability of ketamine to promote a state of attenuated inflammatory mediator expression while maintaining expression of anti-inflammatory mediators. Ketamine inhibited LPSinduced up-regulation of $\mathrm{NF}-x \mathrm{~B}$ expression in lung tissues. NF- $x \mathrm{~B}$ expression is associated with the expression of proinflammatory genes, such as cytokines IL-6, IL- $1 \beta$, and TNF- $\alpha$, which leads to acute lung injury. The inhibition of $\mathrm{NF}-x \mathrm{~B}$ expression may be the molecular mechanism that allows ketamine to protect against acute lung injury in endotoxic shock. There is 
no specific pharmacological therapy for ALI. Ketamine may be effective in decreasing markers of ALI and attenuating the systemic inflammatory response which leads to LPS/sepsis-induced ALI.

\section{Acknowledgements}

This study was supported by the Gazi University Research Foundation (Project No: 01/2011-50).

\section{REFERENCES}

Ahmad N, Chen LC, Gordon MA (2002) Regulation of cyclooxygenase- 2 by nitric oxide in activated hepatic macrophages during acute endotoxemia. I Leukoc Biol 71: 1005-1011.

Andolfatto G, Willman E (2010) A prospective case series of pediatric procedural sedation and analgesia in the emergency department using single-syringe ketamine-propofol combination (ketofol). Acad Emerg Med 17: 194-201.

Ang SF, Sio SW, Moochhala SM (2011) Hydrogen sulfide upregulates cyclooxygenase-2 and prostaglandin E metabolite in sepsis-evoked acute lung injury via transient receptor potential vanilloid type 1 channel activation. I Immunol 187: 4778-4787.

Baetz D, Shaw J, Kirshenbaum LA (2005)Nuclear factor-kappaB decoys suppress endotoxin-induced lung injury. Mol Pharmacol 67: 977-979.

Baeuerle PA (1998) I-kappaB-NF-kappaB structures: at the interface of inflammation control. Cell 95: 729-731.

Barrientos-Vega R, Mar Sánchez-Soria M, Morales-García C, RobasGómez A, Cuena-Boy R, Ayensa-Rincon A (1997) Prolonged sedation of critically ill patients with midazolam or propofol: impact on weaning and costs. Crit Care Med 25: 33-40.

Bernard GR, Artigas A, Brigham KL, Carlet J, Falke K, Hudson $\mathrm{L}$ et al. (1994) The American-European consensus conference on ARDS. Definitions, mechanisms, relevant outcomes and clinical trial coordination. Am J Respir Crit Care Med 149: 818-824.

Blackwell TS, Christman JW (1997) The role of nuclear factor-kappa $\mathrm{B}$ in cytokine gene regulation. Am J Respir Cell Mol Biol 17: 3-9.

Bone RC, Grodzin CJ, Balk RA (1997) Sepsis: a new hypothesis for pathogenesis of the disease process. Chest 112: 235-243.

Brierley J, Peters MJ (2008) Distinct hemodynamic patterns of septic shock at presentation to pediatric intensive care. Pediatrics 122: 752-759.

Brigham KL, Meyrick B (1986) Endotoxin and lung injury. Am Rev Respir Dis 133: 913-927.

Callejas NA, Casado M, Díaz-Guerra MJ (2001) Expression of cyclooxygenase- 2 promotes the release of matrix metalloproteinase- 2 and -9 in fetal rat hepatocytes. Hepatology 33: 860-867.

Chen RM, Chen TL, Lin YL, Chen TG, Tai YT (2005) Ketamine reduces nitric oxide biosynthesis in human umbilical vein endothelial cells by down-regulating endothelial nitric oxide synthase expression and intracellular calcium levels. Crit Care Med 33: 1044-1049.

Chen TL, Chang CC, Lin YL, Ueng YF, Chen RM (2009) Signaltransducing mechanisms of ketamine-caused inhibition of interleukin-1 beta gene expression in lipopolysaccharide-stimulated murine macrophage-like Raw 264.7 cells. Toxicol Appl Pharmacol 240: 15-25.

Coates D, Prys-Roberts C, Spelina KR, Monk CR, Norley I (1985) Propofol ('Diprivan') by intravenous infusion with nitrous oxide: dose requirements and haemodynamic effects. Postgrad Med J 61: 76-79.

da Silva FC, do Carmo de Oliveira Cito M, da Silva MI (2010) Behavioral alterations and pro-oxidant effect of a single ketamine administration to mice. Brain Res Bull 83: 9-15.

Gais P, Tiedje C, Altmayr F, Gaestel M, Weighardt H, Holzmann B (2010) TRIF signaling stimulates translation of TNF-alpha mRNA via prolonged activation of MK2. J Immunol 184: 5842-5848.

Gao J, Zeng B, Zhou L, Yuan S, Zhang S (2003) Therapeutic effect of propofol in the treatment of endotoxin-induced shock in rats. J Huazhong Univ Sci Technolog MedSci 23: 320-323.

Gao J, Zhao WX, Zhou LJ, Zeng BX, Yao SL, Liu D, Chen ZQ (2006) Protective effects of propofol on lipopolysaccharide-activated endothelial cell barrier dysfunction. Inflamm Res 55: 385-392.

Gocan NC, Scott JA, Tym LK (2000) Nitric oxide produced via neuronal NOS may impair vasodilatation in septic rat skeletal muscle. Am J Physiol Heart Circ Physiol 278: 1480-1489.

González-Correa JA, Cruz-Andreotti E, Arrebola MM (2008) Effects of propofol on the leukocyte nitric oxide pathway: in vitro and ex vivo studies in surgical patients. Naunyn Schmiedebergs Arch Pharmacol 376: 331-319.

Gragasin FS, Bourque SL, Davidge ST (2013) Propofol increases vascular relaxation in aging rats chronically treated with the angiotensinconverting enzyme inhibitor captopril. Anesth Analg 116: 775-783.

Huet O, Dupic L, Harrois A (2011) Oxidative stress and endothelial dysfunction during sepsis. Front Biosci 16: 1986-1995.

Inada T, Kubo K, Shingu K (2010) Promotion of interferon-gamma production by naturalkiller cells via suppression of murine peritoneal macrophage prostaglandin E2 production using intravenous anesthetic propofol. Int Immunopharmacol 10: 1200-1208.

Irifune M, Shimizu T, Nomoto M, Fukuda T (1992) Ketamine-induced anesthesia involves the N-methyl-D-aspartate receptor-channel complex in mice. Brain Res 596: 1-9.

James R, Glen JB (1980) Synthesis, biological evaluation and preliminary structure-activity considerations of a series of alkylphenols as intravenous anesthetic agents. J Med Chem 23: 1350-1357.

Karin M, Delhase M (2000) The I kappa B kinase (IKK) and NFkappa B: key elements of proinflammatory signalling. Semin Immunol 12: 85-98.

Kawasaki T, Ogata M, Kawasaki C, Ogata J, Inoue Y, Shigematsu A (1999) Ketamine suppresses proinflammatory cytokine production in human whole blood in vitro. Anesth Analg 89: 665-669.

Khutia KS, Mandal CM, Das S, Basu SR (2012) Intravenous infusion of ketamine-propofol can be an alternative to intravenous infusion of fentanyl-propofol for deep sedation and analgesia in peadiatric patients undergoing emergency short surgical procedures. Indian J Anaesth 56: 145-150.

Koga K, Ogata M, Takenaka I, Matsumoto T, Shigematsu A (1994) Ketamine suppresses tumor necrosis factor-alpha activity and mortality in carrageenan-sensitized endotoxin shock model. Circ Shock 44: 160-166.

Lappi-Blanco E, Kaarteenaho-iik R, Maasilta PK (2006) COX-2 is widely expressed in metaplastic epithelium in pulmonary fibrous disorders. Am J Clin Pathol 126: 717-724.

Larsen B, Hoff G, Wilhelm W, Buchinger H, Wanner GA, Bauer M (1998) Effect of intravenous anesthetics on spontaneous and endotoxin-stimulated cytokine response in cultured human whole blood. Anesthesiology 89: 1218-1227.

Lasa M, Mahtani KR, Finch A, Brewer G, Saklatvala J, Clark AR (2000) Regulation of cyclooxygenase 2 mRNA stability by the mitogen-activated protein kinase p38 signaling cascade. Mol Cell Biol 20: 4265-4274.

Liu FL, Chen TL, Chen RM (2012) Mechanisms of ketamine-induced immunosuppression. Acta Anaesthesiol Taiwan 50: 172-177.

Liu YC, Chang AY, Tsai YC (2009) Differential protection against oxidative stress and nitric oxide overproduction in cardiovascular and pulmonary systems by propofol during endotoxemia. I Biomed Sci 15: 16-18.

Loh G, Dalen D (2007) Low-dose ketamine in addition to propofol for procedural sedation and analgesia in the emergency department. Ann Pharmacother 41: 485-492.

Ma L, Wu XY, Zhang LH, Chen WM, Uchivama A, Mashimo T, Fujino Y (2013) Propofol exerts anti-inflammatory effects in rats with lipopolysaccharide-induced acute lung injury by inhibition of CD14 and TLR4 expression. Braz I Med Biol Res 46: 299-305.

Marinelli WA, Ingbar DH (1994) Diagnosis and management of acute lung injury. Clin Chest Med 15: 517-146.

Min TJ, Kim WY, Jeong WJ, Choi HJ, Lee SY, Kim HJ, Park CY (2012) Effect of ketamine on intravenous patient-controlled analgesia using hydromorphone and ketorolac after the Nuss surgery in pediatric patients. Korean J Anesthesiol 62: 142-147.

Miranda KM, Espey MG, Wink DA (2001) A rapid, simple spectrophotometric method for simultaneous detection of nitrate and nitrite. Nitric Oxide 5: 62-71.

Murphy PG, Myers DS, Davies MJ, Webster NR, Jones JG (1992) The antioxidant potential of propofol (2,6-diisopropylphenol). Br J Anaesth 68: 613-618.

Ogawa A, Uemura M, Kataoka Y, Ol K, Inokuchi T (1993) Effects of ketamine on cardiovascular responses mediated by N-methyl-Daspartate receptor in the rat nucleus tractus solitarius. Anesthesiology 93: $163-167$.

Okamoto I, Abe M, Shibata K (2000) Evaluating the role of inducible nitric oxide synthase using a novel and selective inducible nitric oxide synthase inhibitor in septic lung injury produced by cecal ligation and puncture. Am J Respir Crit Care Med 162: 716-722.

Randolph AG (2009) Management of acute lung injury and acute respiratory distress syndrome in children. Crit Care Med 37: 2448-2454.

Zhao W, Liu M, Kirkwood KL (0000) p38alpha stabilizes interleukin-6 mRNA via multiple AU-rich elements. J Biol Chem 283: 1778-1785. 